\title{
The Dallas-Fort Worth Earthquake Sequence: October 2008 through May 2009
}

\author{
by Cliff Frohlich, Chris Hayward, Brian Stump, and Eric Potter
}

\begin{abstract}
This paper describes a sequence of small earthquakes $\left(m_{\mathrm{b}} \leq 3.3\right)$ that occurred at the Dallas-Fort Worth Airport, Texas, between 30 October 2008 and 31 May 2009. Analysis of records at regional station WMOK identified more than 180 earthquakes in the sequence; about 90 percent occurred in four clusters on 30 October-1 November, 20 November, 26 December and 15-17 May. After the sequence began, a six-station temporary local network obtained high-quality three-component records for 11 earthquakes occurring between 20 November and 1 December. Analysis of these data demonstrated that all 11 earthquakes originated from a focus near $32.855^{\circ} \mathrm{N}, 97.051^{\circ} \mathrm{W}$, with an estimated depth $\sim 4.4 \mathrm{~km}$. This location is less than $0.5 \mathrm{~km}$ from a well completed in August 2008 that extends to a depth of $4.2 \mathrm{~km}$, drilled to dispose of brines collected during flowback of hydraulic fracturing fluids associated with the production of natural gas. Brine disposal commenced at the well on 12 September 2008. Seismograms and $(S-P)$ intervals for the earthquakes are similar though not identical, and relative locations indicate they occurred along a north-northeast-south-southwest trend with horizontal and vertical dimensions of $\sim 1.1 \mathrm{~km}$ and $0.2 \mathrm{~km}$, respectively. This trend is approximately coincident with that of a mapped normal fault in the subsurface, and consistent with the maximum horizontal in situ stress direction. Because of the absence of previous historical earthquakes, the proximity of the brine disposal well, and the similarity with other documented cases of induced seismicity, it seems likely that fluid injection induced the 2008-2009 sequence.
\end{abstract}

\section{Introduction}

Between 31 October 2008 and 16 May 2009 many Dallas-Fort Worth (DFW) area residents felt several small earthquakes; those located by the National Earthquake Information Center (NEIC) had magnitudes between 2.2 and 3.3 (Figs. 1 and 2; Table 1). These events are of scientific interest for three reasons: (1) because Tarrant and Dallas counties, home to Fort Worth and Dallas, respectively, constitute a major urban center with a combined population of about four million; (2) because earthquakes have not occurred here previously in historic times (Frohlich and Davis, 2002); and (3) because there has been a significant increase since 2002 in permits authorizing drilling and hydraulic fracturing to produce natural gas from the Barnett shale, a Mississippian formation that underlies thousands of square kilometers in the Fort Worth and adjoining basins, including all of Tarrant County (Montgomery et al., 2005).

Following the onset of seismicity recognized in October, seismologists from Southern Methodist University (SMU) borrowed six PASSCAL Rapid Array Mobilization Program (RAMP) three-component broadband seismographs and operated them at six sites in Tarrant and Dallas counties (Table 2 and Fig. 2), collecting data between 9 November 2008 and 2 January 2009. Although the NEIC reported no felt earthquakes during this period, the SMU stations recorded numerous local earthquakes, including 11 especially well-recorded events (Table 1), nine occurring in a swarm on 20 November and the others on 28 November and 2 December.

The principal objective of this paper is to describe the October 2008-May 2009 seismicity, concentrating especially on data collected by the SMU network. We augment this with seismograms recorded at a continuously operating station (Wichita Mountain, Oklahoma), which exhibits exceptionally clear signals (see Fig. 3) from numerous small earthquakes that appear to originate from the DFW focus. A preliminary analysis of these data appears in Frohlich et al. (2010).

Another objective of this paper is to assess the relationship between the DFW earthquakes and activities associated with the natural gas production in Tarrant County. Although the DFW earthquakes caused little property damage, regional newspaper stories described interviews with petroleum geologists, industry spokesmen, university scientists, and 


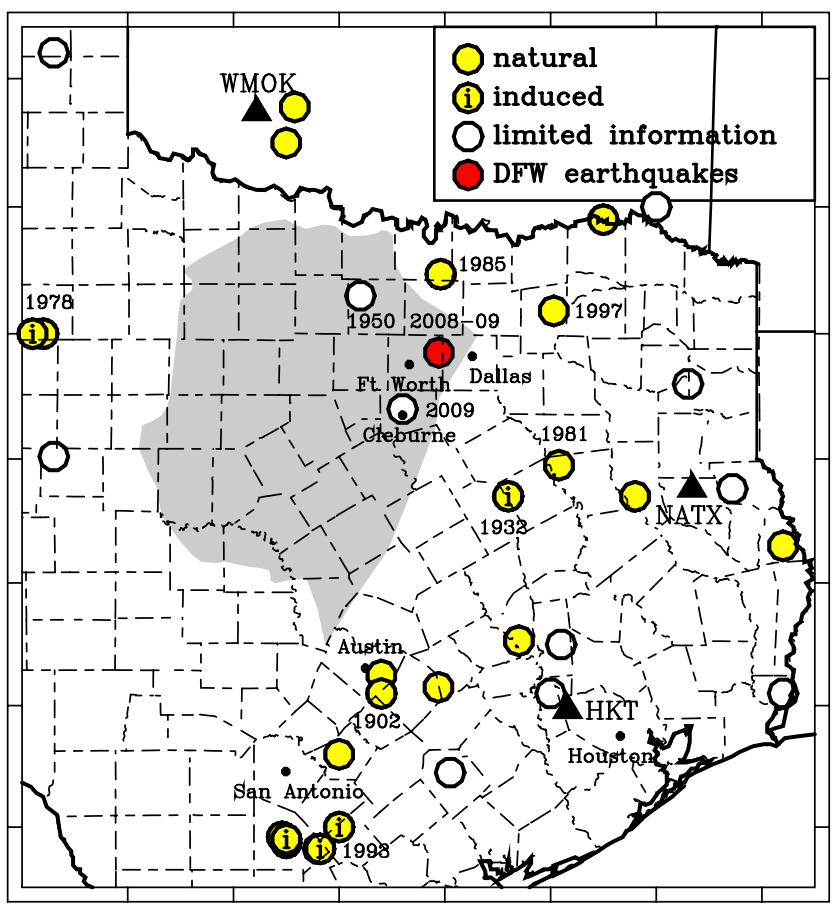

Figure 1. Map of eastern Texas showing historically felt earthquakes (circles) and continuously operating seismograph stations (triangles). Shaded area indicates the subsurface extent of the Barnett shale, the focus of increased natural gas production since about 2000. Epicenters are updated from Frohlich and Davis (2002), and Barnett shale is as mapped by Pollastro et al. (2007). Earthquakes labeled 1902, 1932, 1978, 1981, 1985, 1993, 1997, and 2009 are mentioned in the text and occurred near the towns of Austin, Mexia, Snyder, Center, Valley View, Fashing, Commerce, and Cleburne, respectively. The color version of this figure is available only in the electronic edition.

concerned local residents, framed as a debate concerning whether drilling caused the earthquakes, and whether much larger earthquakes are likely to occur. In this paper we investigate which activities related to natural gas recovery might possibly have induced the earthquakes, that is, drilling, hydrofracture, production, or fluid waste disposal. We will also compare the properties of the DFW sequence to natural and human-induced earthquake sequences in Texas and elsewhere (e.g., see Phillips et al., 2002; Majer et al., 2007; Suckale, 2009, 2010).

\section{When Quakes Occurred: Analysis of WMOK Data}

The 31 October-1 November 2008 felt earthquakes produced readable signals at several regional stations, allowing the NEIC to locate 10 epicenters. Station WMOK $\left(\Delta=2.36^{\circ}\right.$; Fig. 1$)$, a part of the USGS Advanced National Seismic System, recorded exceptionally clear signals (Fig. 3) for the DFW earthquakes. In contrast, signals were barely readable or absent on other nearby stations: NATX $(\Delta=$ $\left.2.30^{\circ}\right)$, HKT $\left(\Delta=3.06^{\circ}\right)$, and JCT $\left(\Delta=3.32^{\circ}\right)$. Signals for many of the larger events were visible at some other regional stations, including the TXAR array in West Texas.

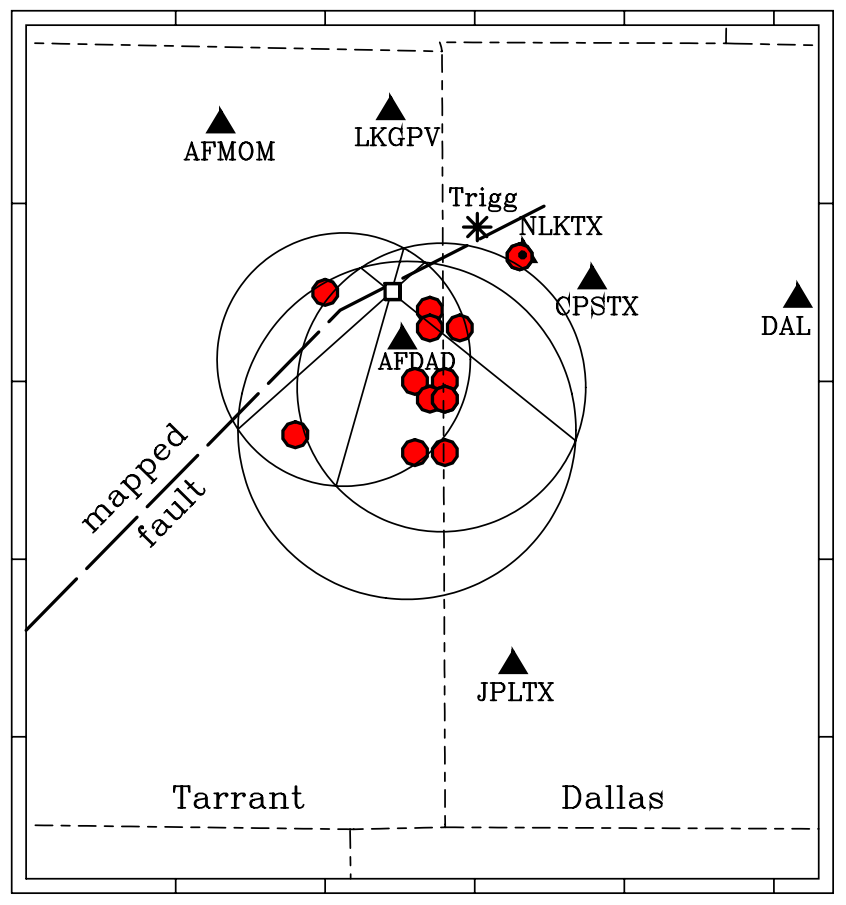

Figure 2. Map of the boundary between Tarrant and Dallas counties, showing epicenters (filled circles) reported by the NEIC between 31 October 2008 and 16 May 2009 (Table 1, NEIC events), and the location of the DFW focus (small square with 1-km sides; see Fig. 8) where epicenters determined in this study occurred (Table 1, SMU events). Triangles are station locations for station DAL (see text) and for the temporary seismograph network deployed between 9 November 2008 and 2 January 2009 (Table 2). Thick dashed line is normal fault mapped by Ewing (1990); asterisk (*) indicates location of Trigg well no. 1 providing velocity information constraining crustal structure. Large circles show how Wadati's (1928) method fixes the location: these circles are surface intersection of spheres fixed by ratios of $(S-P)$ times at stations AFMOM, CPSTX, and LKGPV with respect to AFDAD; the three chords meet where the three spheres intersect at $32.850^{\circ} \mathrm{N}$, $97.056^{\circ} \mathrm{W}$, depth $6.0 \mathrm{~km}$. The color version of this figure is available only in the electronic edition.

At this time the EarthScope Transportable array included operating stations in west Texas and the Texas panhandle at distances of $5^{\circ}$ and greater; however, none we inspected recorded signals as numerous or with the high signal-tonoise ratios of those at WMOK.

We analyzed signals recorded at WMOK between 1 January 2008 and 31 May 2010 to evaluate the time history of DFW activity. To identify events, we band-pass-filtered (corners $1.0 \mathrm{~Hz}$ and $10 \mathrm{~Hz}$ ) the broadband signal on the east component of WMOK, and performed a cross correlation with a particularly well-recorded reference event, the earthquake of 31 October 2008 at 0623 (GMT; NEIC-5 in Table 1). We inspected all events with amplitudes exceeding 50 digital units and having a cross correlation exceeding 0.45 . Nearly all such events had $(S-P)$ times of $\sim 30.75 \mathrm{~s}$ and/or $S$-coda character similar to the reference event.

We thus identified 183 earthquakes apparently originating from the DFW focus (Fig. 4). The earliest identified event 
Table 1

Dallas-Fort Worth Earthquakes Analyzed in this Paper

\begin{tabular}{cccccccc}
\hline Identifier & Date $(\mathrm{dd} / \mathrm{mm} / \mathrm{yy})$ & Origin Time & Latitude $\left({ }^{\circ} \mathrm{N}\right)$ & Longitude $\left({ }^{\circ} \mathrm{W}\right)$ & Depth $(\mathrm{km})$ & Magnitude & Felt* \\
\hline NEIC-1 & $31 / 10 / 08$ & $04: 25: 52.29$ & 32.80 & 97.02 & 5 & 2.6 & III \\
NEIC-2 & $31 / 10 / 08$ & $05: 01: 54.91$ & 32.84 & 97.03 & 5 & 3.0 & IV \\
NEIC-3 & $31 / 10 / 08$ & $05: 33: 45.62$ & 32.87 & 96.97 & 5 & 2.6 & - \\
NEIC-4 & $31 / 10 / 08$ & $05: 46: 31$ & 32.76 & 97.02 & 5 & 2.5 & - \\
NEIC-5 & $31 / 10 / 08$ & $06: 23: 44.12$ & 32.80 & 97.04 & 5 & 2.6 & - \\
NEIC-6 & $31 / 10 / 08$ & $07: 58: 23.91$ & 32.83 & 97.01 & 5 & 2.9 & F \\
NEIC-7 & $31 / 10 / 08$ & $20: 54: 18.81$ & 32.83 & 97.03 & 5 & 2.9 & F \\
NEIC-8 & $31 / 10 / 08$ & $21: 01: 01.77$ & 32.79 & 97.03 & 5 & 2.9 & F \\
NEIC-9 & $01 / 11 / 08$ & $11: 53: 46.65$ & 32.76 & 97.04 & 5 & 2.5 & - \\
NEIC-10 & $01 / 11 / 08$ & $11: 54: 30.19$ & 32.87 & 96.97 & 5 & 2.7 & III \\
NEIC-11 & $16 / 05 / 09$ & $16: 24: 06.57$ & 32.79 & 97.02 & 8 & 3.3 & IV \\
NEIC-12 & $16 / 05 / 09$ & $16: 58: 37.69$ & 32.85 & 97.10 & 5 & 3.0 & - \\
NEIC-13 & $16 / 05 / 09$ & $17: 53: 09.36$ & 32.77 & 97.12 & 5 & 2.7 & II \\
NEIC-14 & $16 / 05 / 09$ & $18: 02: 23$ & 32.79 & 97.02 & 5 & 2.6 & - \\
SMU-1 & $20 / 11 / 08$ & $09: 58: 23.91$ & 32.8539 & 97.0519 & 4.44 & 1.9 & - \\
SMU-2 & $20 / 11 / 08$ & $10: 00: 15.69$ & 32.8543 & 97.0519 & 4.34 & 1.9 & - \\
SMU-3 & $20 / 11 / 08$ & $10: 00: 57.67$ & 32.8571 & 97.0499 & 4.34 & 2.1 & - \\
SMU-4 & $20 / 11 / 08$ & $10: 12: 14.37$ & 32.8576 & 97.0493 & 4.35 & 2.3 & - \\
SMU-5 & $20 / 11 / 08$ & $10: 14: 27.21$ & 32.8554 & 97.0512 & 4.44 & 1.7 & - \\
SMU-6 & $20 / 11 / 08$ & $10: 20: 21.57$ & 32.8582 & 97.0493 & 4.44 & 1.7 & - \\
SMU-7 & $20 / 11 / 08$ & $10: 32: 39.15$ & 32.8498 & 97.0532 & 4.46 & 2.3 & - \\
SMU-8 & $20 / 11 / 08$ & $12: 23: 49.12$ & 32.8494 & 97.0533 & 4.43 & 2.1 & - \\
SMU-9 & $20 / 11 / 08$ & $12: 26: 48.58$ & 32.8507 & 97.0532 & 4.34 & 2.2 & - \\
SMU-10 & $28 / 11 / 08$ & $01: 49: 29.54$ & 32.8591 & 97.0497 & 4.35 & 2.3 & - \\
SMU-11 & $01 / 12 / 08$ & $21: 26: 33.96$ & 32.8592 & 97.0482 & 4.43 & 2.3 & - \\
\hline
\end{tabular}

*Roman numerals refer to maximum modified Mercalli intensity as reported by the NEIC. F indicates that the NEIC reported that the event was felt but gave no intensity.

${ }^{\dagger}$ Hypocenters with NEIC identifiers are as reported by the National Earthquake Information Center.

${ }^{\ddagger}$ Hypocenters with SMU identifiers are events recorded by the SMU temporary network and relocated in this study.

was an $M 1.7$ earthquake occurring on 30 October 2008 at 0101 (GMT), about a day before the first earthquake was felt on 31 October (Table 1, NEIC events). Event 183, with M 1.8, occurred on 19 May 2009 at 0834 (GMT). The majority of identified events cluster within four discrete time periods; 97 occurred between 30 October-1 November; 12 on 20 November; 17 on 26 December, and 40 on 15-17 May. Moreover, visual inspection of seismograms at WMOK suggests our criteria for identifying DFW events are conservative; that is, the compiled list does not include numerous similar signals too small to meet the criteria described previously and/or partially obscured within the coda of larger events (e.g., see Fig. 3). [Later note: Subsequently we have applied the same criteria to WMOK data for the period 1 June 2009 to March 2010 and identified only four additional earthquakes: 30 June 20090417 (GMT) M 1.9; 26 December 20091622 and 1625 (GMT) $M 1.9$ and $M$ 1.8; and 6 March $2010 M$ 2.8.]

We estimated magnitudes $M$ by comparing peak amplitudes $A$ to amplitudes of events reported by the NEIC, assuming that $M$ is proportional to $\log _{10} A$. We estimated scalar moment $M_{0}$ using the relationship $M=-6+(2 / 3)$ $\log _{10} M_{0}[\mathrm{Nm}]$. The six largest events account for about 40 percent of the scalar moment for the sequence (Fig. 4);

Table 2

Stations in the 2008 SMU Network, and Range and Mean of $(S-P)$ Times Determined for the 11 Well-Recorded Earthquakes (Table 1, SMU Events)*

\begin{tabular}{cccccccc}
\hline Station Name & Latitude $\left({ }^{\circ} \mathrm{N}\right)$ & Longitude $\left({ }^{\circ} \mathrm{W}\right)$ & Operating $(\mathrm{dd} / \mathrm{mm}-\mathrm{dd} / \mathrm{mm})$ & $(S-P)_{\min }(\mathrm{s})$ & $(S-P)$ mean & $(S-P)_{\max }(\mathrm{s})$ & Number $(S-P)$ \\
\hline AFDAD & 32.8227 & 97.0484 & $09 / 11-19 / 12$ & 1.020 & 1.069 & 1.130 \\
AFMOM & 32.9440 & 97.1699 & $09 / 11-05 / 12$ & 2.505 & 2.541 & 2.570 \\
CPSTX & 32.8565 & 96.9215 & $12 / 11-23 / 12$ & 2.170 & 2.200 & 2.240 \\
JPLTX & 32.6401 & 96.9743 & $14 / 11-30 / 12$ & 3.768 & 3.817 & 3.865 \\
LKGPV & 32.9515 & 97.0562 & $09 / 11-22 / 12$ & 1.980 & 2.019 & 2.078 \\
NLKTX & 32.8712 & 96.9677 & $06 / 12-02 / 01$ & - & - & - & - \\
\hline
\end{tabular}

* Note that there are fewer observations at JPLTX and LKGPV than at the other stations. 


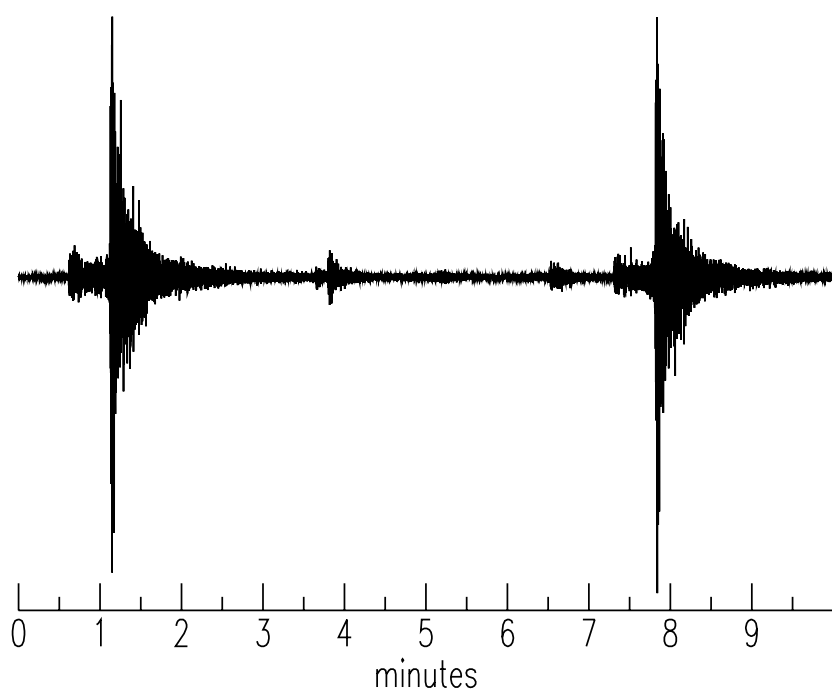

Figure 3. East-component seismogram recorded beginning 205431 October 2008 (GMT) at station WMOK, situated at a distance $\Delta$ of $2.36^{\circ}$ from the DFW focus. Note clear $P$ and $S$ arrivals for two earthquakes (NEIC-7 and NEIC-8 in Table 1). Also note the presence of smaller events apparently from the same focus.

all six are members of the 30 October-1 November and 1517 May clusters, and all were reported by the NEIC. The magnitude-frequency plot (Fig. 5) is consistent with a $b$ value (slope of $\log _{10} N$ versus $M$ ) of $\sim 1.3$ and the lowmagnitude rolloff suggests that our WMOK-identified event list is complete down to magnitudes of about 2.0.

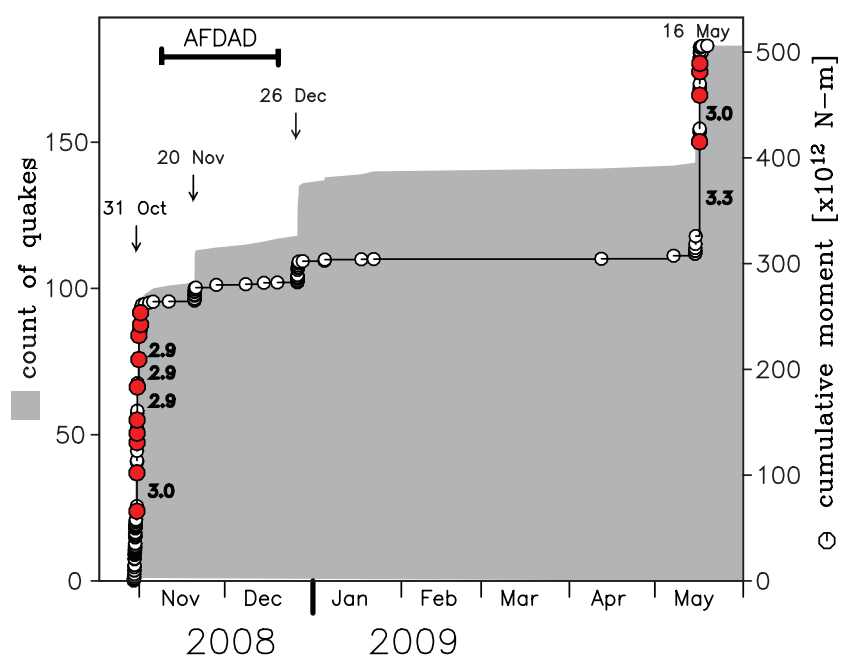

Figure 4. Time history of earthquake activity at the DFW focus as determined by analysis of seismograms at station WMOK (Wichita Mountain, Oklahoma). Shaded area and left axis indicate cumulative number of events identified; circles and right axis indicate cumulative scalar moment; labels identify times of particular swarms. Filled circles are events reported by the NEIC. Bar at upper left indicates period when closest station AFDAD was operational. The color version of this figure is available only in the electronic edition.

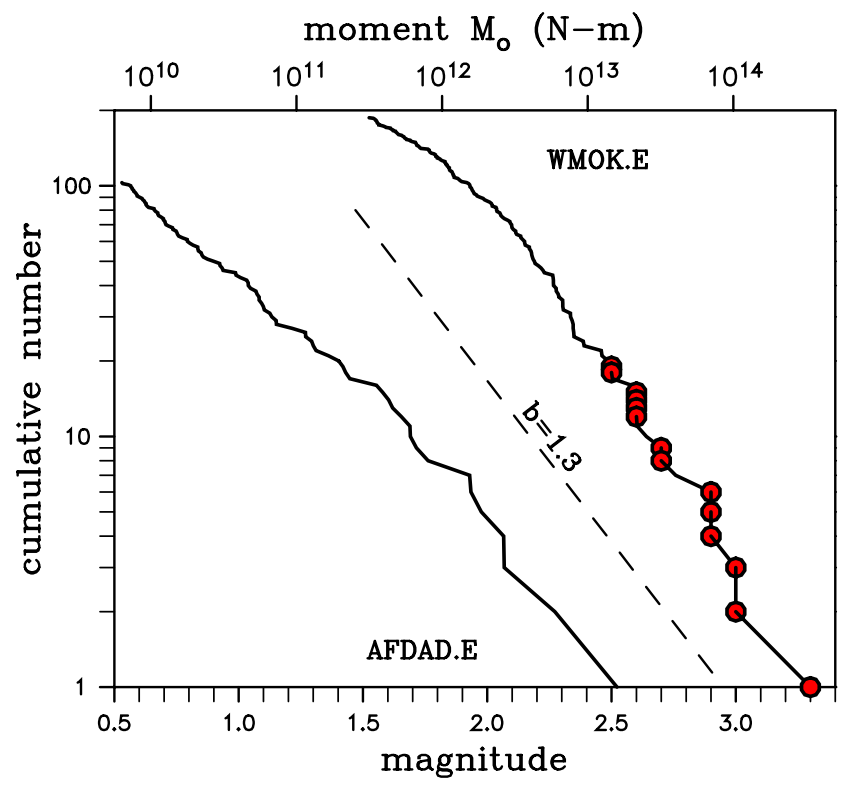

Figure 5. Size distributions of DFW earthquakes as recorded at stations WMOK and AFDAD. Identification as a DFW event as well as event magnitudes and scalar moments are determined as described in the text. Filled circles indicate magnitudes of events reported by the NEIC. Note that the $b$ value (slope of log-number versus magnitude curve) is about 1.3 , and that the apparent magnitudes of completeness at WMOK and AFDAD are about 2.0 and 1.5 , respectively. The color version of this figure is available only in the electronic edition.

\section{Where Quakes Occurred: Analysis of Data from the SMU Network}

Although the NEIC reported no DFW events while three or more stations of the temporary local network were in place, numerous events identified at WMOK (Fig. 4) did occur during this period, including 16 while AFDAD, the closest $(\Delta \sim 3 \mathrm{~km})$ and most sensitive station was operating. We performed a cross-correlation analysis for AFDAD similar to that described earlier for WMOK, and identified a total of 103 events apparently from the DFW focus. The magnitude-frequency plot (Fig. 5) indicates detection is complete at AFDAD down to a magnitude of about 1.5. Most of the AFDAD events not identified at WMOK were too poorly recorded at other stations in the SMU network to permit accurate location.

\section{Arrival Times}

A preliminary search identified 11 earthquakes (Table 1, SMU events) with exceptionally clear $P$ and $S$ arrivals on stations AFDAD, AFMOM, and CPSTX (Fig. 2). Arrival times at these stations were picked by inspecting pairs of signals (see Fig. 6); because the sampling interval was $0.005 \mathrm{~s}$ and because the phases were impulsive, we estimate these picks have a relative accuracy of $\sim 0.02 \mathrm{~s}$. Whenever possible, we read arrival times at the remaining stations (LKGPV and JPLTX); however, these stations were less sensitive and their 


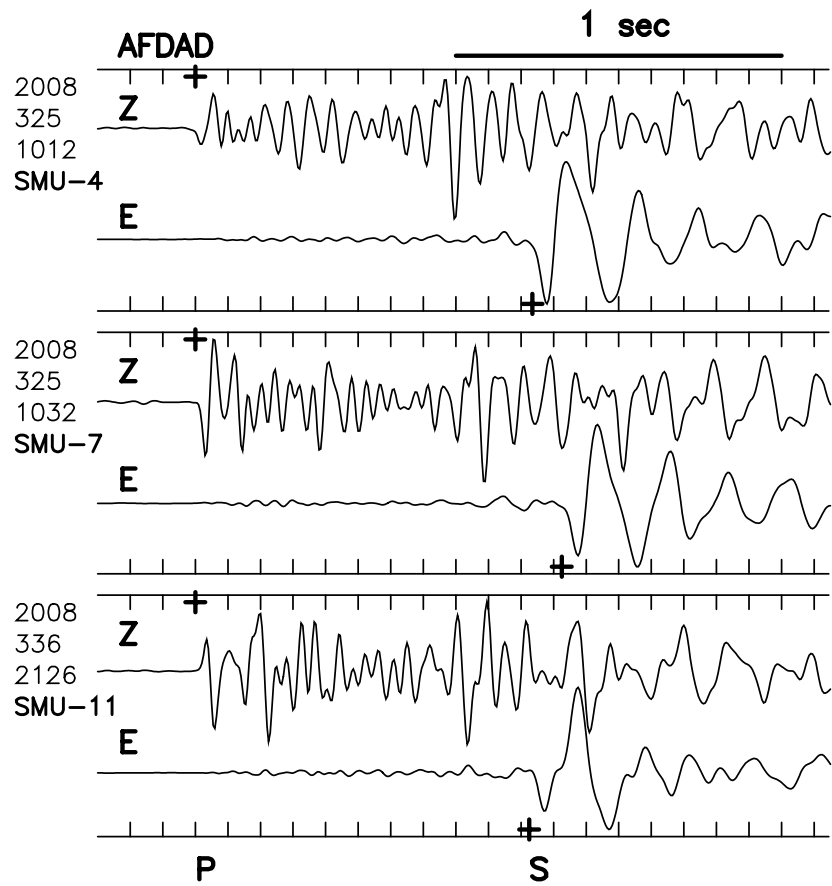

Figure 6. Examples of vertical (Z)- and east (E)-component seismograms recorded at $\operatorname{AFDAD}\left(\Delta \sim 3 \mathrm{~km}\right.$, azimuth $177^{\circ} \mathrm{E}$ of north). Time tics are at intervals of $0.1 \mathrm{~s}$; plus $(+)$ symbols indicate $P$ and $S$ arrival picks; all records are aligned with the $P$ pick. Note that the signals are not identical: the first motion for the SMU-11 record is up; $(S-P)$ interval for SMU-7 is approximately $0.1 \mathrm{~s}$ greater than for the other two events.

relative accuracy was poorer. We estimated that the $V_{P} / V_{S}$ ratio was 1.87 by plotting a Wadati diagram, that is, a graph of time differences of $S$ arrivals versus time differences of $P$ arrivals at pairs of stations.

\section{Locations: Objectives and Strategy}

The remainder of this section describes hypocentral locations we determined for this group of 11 earthquakes (Table 1, SMU events). Our primary objective was to determine the relationship between this group and the locations of injection and production wells. Thus, to assess systematic errors in absolute location, we used three different location methods utilizing three different velocity models; to minimize the effect of random picking errors, we determined a centroid (average) location for the group. We also applied a fourth method, a relative location method, to evaluate the spatial extent of the group and assess whether locations changed over time.

\section{Centroid Location: Wadati's Method}

We first applied Wadati's (1928) method (see Fig. 2; also Frohlich, 2006, p. 61). Wadati's method does not require specifying the $P$ velocity, the $S$ velocity, or the $V_{P} / V_{S}$ ratio, although it implicitly assumes that $P$ and $S$ velocities are constant. It is thus instructive in areas such as the DFW region where no well-established velocity model is available. The method requires measuring $(S-P)$ intervals at pairs of stations; for stations $i$ and $j$, it assumes the ratio $\Delta_{i} / \Delta_{j}$ of quake-station distances satisfies

$$
\Delta_{i} / \Delta_{j}=(S-P)_{i} /(S-P)_{j}
$$

The locus of points satisfying equation (1) is a sphere. When the stations are separated by distance $D_{i j}$, the center of the sphere lies along a line joining the stations and a distance $D_{i j} /\left[1-\left(\Delta_{i} / \Delta_{j}\right)^{2}\right]$ from station $j$. The radius of the sphere is $D_{i j}\left(\Delta_{i} / \Delta_{j}\right) / \operatorname{abs}\left[1-\left(\Delta_{i} / \Delta_{j}\right)^{2}\right]$. When $(S-P)$ intervals are available for three pairs of stations, the intersection of three spheres determines a unique hypocenter.

This method was applied using mean $(S-P)$ intervals (Table 2) for the station pairs AFMOM/AFDAD, CPSTX/ AFDAD, and LKGPV/AFDAD. The resulting hypocenter (Fig. 2 and Table 3 ) is at $32.850^{\circ} \mathrm{N}, 97.056^{\circ} \mathrm{W}$ with a depth of $6.0 \mathrm{~km}$ and is consistent with a quake-to-station $P$ velocity of $5.72 \mathrm{~km} / \mathrm{s}$ and $V_{P} / V_{S}$ of 1.87 . We obtained a nearly identical location when we used the JPLTX/AFDAD ratio in place of LKGPV/AFDAD.

\section{Centroid Location: Flat Layered Model}

For the second location method, we used a conventional location program (Frohlich, 1993) requiring specification of constant-velocity flat crustal layers. The velocity model was based on published well-log information (see Fig. 7) for Trigg well no. 1 (Geotechnical Corporation, 1964), situated at $32.88669^{\circ} \mathrm{N}, 96.99832^{\circ} \mathrm{W}$, a distance of $\sim 6 \mathrm{~km}$ from the DFW epicenters. We specified three layers based on

Table 3

Comparison of Locations for the DFW Focus as Determined by Different Methods*

\begin{tabular}{|c|c|c|c|c|}
\hline Model/Method & Latitude $\left({ }^{\circ} \mathrm{N}\right)$ & Longitude $\left({ }^{\circ} \mathrm{W}\right)$ & Depth (km) & Comments \\
\hline Wadati (1928): $(S-P)$ ratios & 32.850 & 97.056 & 6.0 & $\begin{array}{l}\text { Method constrains best-fitting half-space model fitting } \\
\text { observations; result: } V_{P}=5.72 \mathrm{~km} / \mathrm{s} ; V_{P} / V_{S}=1.87\end{array}$ \\
\hline Trigg well: 3-Layer model & 32.852 & 97.054 & 4.8 & Conventional location method \\
\hline Trigg well: Linear velocity model & 32.855 & 97.051 & 4.4 & $\begin{array}{l}\text { Preferred location; } V_{P}=3.2+0.7 Z \mathrm{~km} / \mathrm{s}(Z \text { depth in } \mathrm{km}) \\
\text { fits well interval velocity and allows locations having good } \\
\text { agreement with } P \text { and } S \text { times }\end{array}$ \\
\hline
\end{tabular}

*Values are mean values determined from travel times recorded at the SMU network for 11 well-recorded events (Table 1, SMU events). 
the well-log data: a surface layer with velocity $2.9 \mathrm{~km} / \mathrm{s}$ and thickness $600 \mathrm{~m}$; a second layer with velocity $4.0 \mathrm{~km} / \mathrm{s}$ and thickness $2.15 \mathrm{~km}$, corresponding to the Pennsylvanian; and a half-space representative of Ordovician and older rocks with velocity $6.3 \mathrm{~km} / \mathrm{s}$. In all layers we fixed $V_{P} / V_{S}$ to be 1.87. Hypocenters determined with this model for the 11 well-recorded earthquakes had root mean square (rms) residuals ranging from $0.02-0.06 \mathrm{~s}$. The mean of the 11 locations was $32.852^{\circ} \mathrm{N}, 97.054^{\circ} \mathrm{W}$ with a depth estimate of $4.8 \mathrm{~km}$. This location is about $180 \mathrm{~m}$ north, $205 \mathrm{~m}$ east, and $1.2 \mathrm{~km}$ shallower than the Wadati-method location (Table 3).

\section{Centroid Location: Linear Velocity Model}

Although the Pennsylvanian and Ordovician strata associated with the Barnett shale are familiar to Texas geologists, modeling them as constant-velocity layers does not provide a particularly good fit to the Trigg well interval velocity data (see Fig. 7). The velocity instead increases approximately linearly with depth. Thus, our third location method assumed a linear velocity model of the form $V_{P}=V_{0}+s Z$, where $Z$ is depth and $s$ is a constant. For such a model the expressions for distance $\Delta(p)$ and travel time $T(p)$ as a function of ray parameter $p$ are integrals with respect to $Z$ that can be solved analytically. Thus, one can calculate travel times and their derivatives to any desired degree of precision and use this as the basis for locating hypocenters either by using grid-search or conventional least-squares methods.

We used the linear velocity model $V_{P}=3.2+$ $0.7 Z \mathrm{~km} / \mathrm{s}$ (units of $Z$ are $\mathrm{km}$ ) and applied it to $P$ and $S$ observations at AFDAD, AFMOM, CPSTX, and LKGPV (Table 2) to determine a location for the DFW focus (again, $V_{P} / V_{S}$ of 1.87). The resulting location, with an rms residual of less than $0.001 \mathrm{~s}$, placed the DFW focus at $32.855^{\circ} \mathrm{N}$, $97.051^{\circ} \mathrm{W}$, and depth $4.4 \mathrm{~km}$. This location is about $550 \mathrm{~m}$ north, $460 \mathrm{~m}$ east, and $1.6 \mathrm{~km}$ shallower than the Wadatimethod location (see Fig. 8 and Table 3). The region occupied by hypocenters with rms residuals within $0.02 \mathrm{~s}$ of the optimum location extends $\pm 410 \mathrm{~m}$ horizontally and

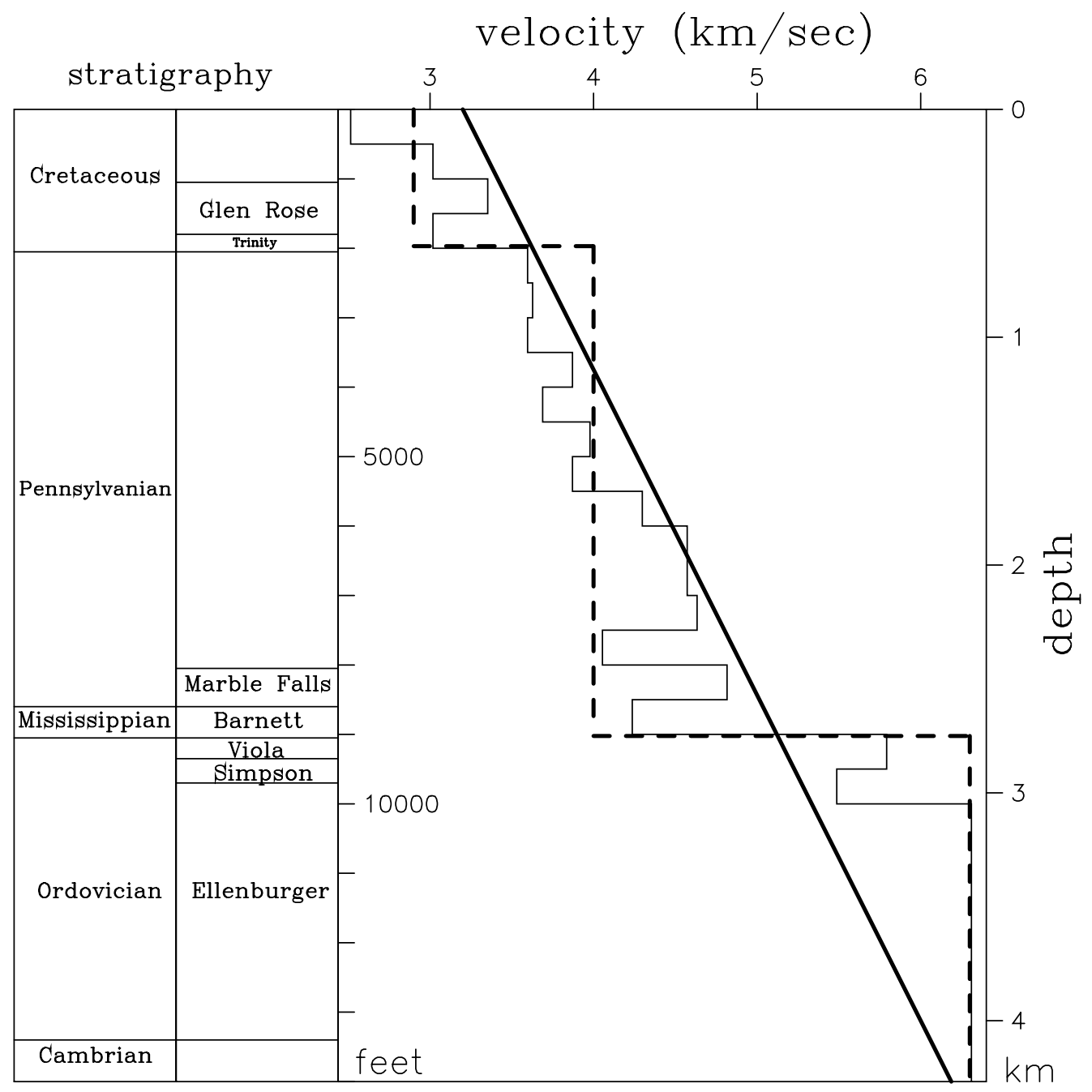

Figure 7. Interval velocities and stratigraphy reported by Geotechnical Corporation (1964) for Trigg well no. 1, and velocity models used to constrain hypocentral locations. Thick solid line is linear model; dashed line is three-layer model. 
$\pm 589 \mathrm{~m}$ depth (see Fig. 8); for a more conservative rms uncertainty of $0.04 \mathrm{~s}$, the range of permissible locations and depths are $\pm 820 \mathrm{~m}$ and $\pm 1.18 \mathrm{~km}$, respectively. These uncertainties are approximately consistent with the differences between absolute locations for the DFW focus as determined by the three methods described in this paragraph and the previous text.

\section{Relative Locations}

Finally, for the fourth location method, we determined precise relative locations for the 11 well-recorded earthquakes. We fixed the mean location for the 11 events at the linear-model value determined earlier. We then determined relative locations using $(S-P)$ interval differences at AFDAD, AFMOM, and CPSTX (Table 2) and the average $P$ and $S$ velocities determined using Wadati's method. Thus, if $\Delta t_{k 0}^{i}$ is the difference at station $i$ between the $(S-P)$ interval for the $k$ th earthquake and the mean $(S-P)$ interval, then

$$
\begin{aligned}
\Delta t_{k 0}^{i}= & {\left[\left(V_{P}-V_{S}\right) / V_{P} V_{S}\right]\left(\cos \theta_{0}^{i} \sin \alpha_{0}^{i} X_{k 0}^{\mathrm{N}}\right.} \\
& \left.+\sin \theta_{0}^{i} \sin \alpha_{0}^{i} X_{k 0}^{\mathrm{E}}+\cos \alpha_{0}^{i} X_{k 0}^{\mathrm{Z}}\right),
\end{aligned}
$$

(a)

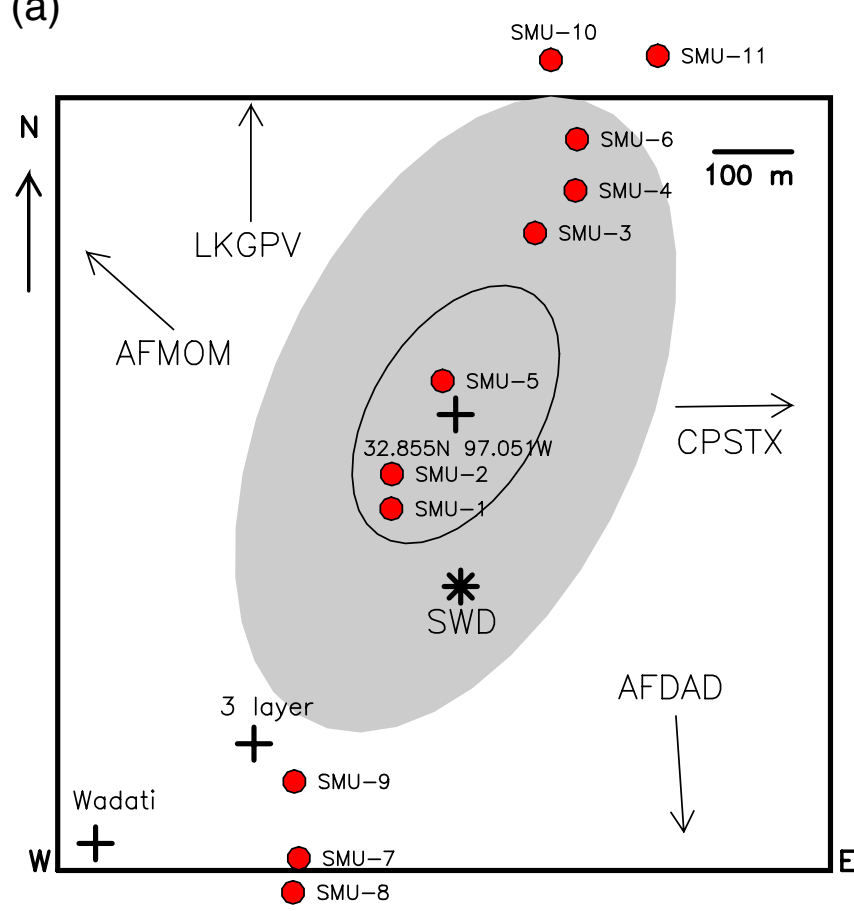

where $\theta_{0}^{i}$ and $\alpha_{0}^{i}$ are the azimuth and take-off angles for station $i$ with respect to the mean location; $X_{k 0}^{\mathrm{N}}, X_{k 0}^{\mathrm{E}}$, and $X_{k 0}^{Z}$ are the north, east, and vertical differences in relative location; and $V_{P}$ and $V_{S}$ are the $P$ and $S$ velocities. Equation (2) has a unique solution if there are time differences available for three stations.

The results (Fig. 8) indicate that all 11 earthquakes occurred on Dallas-Fort Worth airport property, and occupy a region with horizontal dimensions of about $1100 \mathrm{~m}$ and a depth range of $125 \mathrm{~m}$. For three reasons, we believe the epicentral variations evident in Figure 8 are real; that is, we believe not all of the events originated from an identical focus. First, location simulations assuming reading errors of $\pm 0.02 \mathrm{~s}$ at the three stations shift the locations by only about $\pm 200 \mathrm{~m}$ horizontally and $\pm 125 \mathrm{~m}$ vertically, significantly less than the variation observed among the actual locations. Second, close visual inspection of the seismograms (Fig. 6) indicates that $(S-P)$ intervals are not identical at individual stations; for example, at AFDAD $(S-P)$ varies by as much as $0.1 \mathrm{~s}$. Finally, visual inspection of seismograms at individual stations indicates that events are not all identical, suggesting that their locations and/or focal mechanisms differ (see Fig. 6). (b)

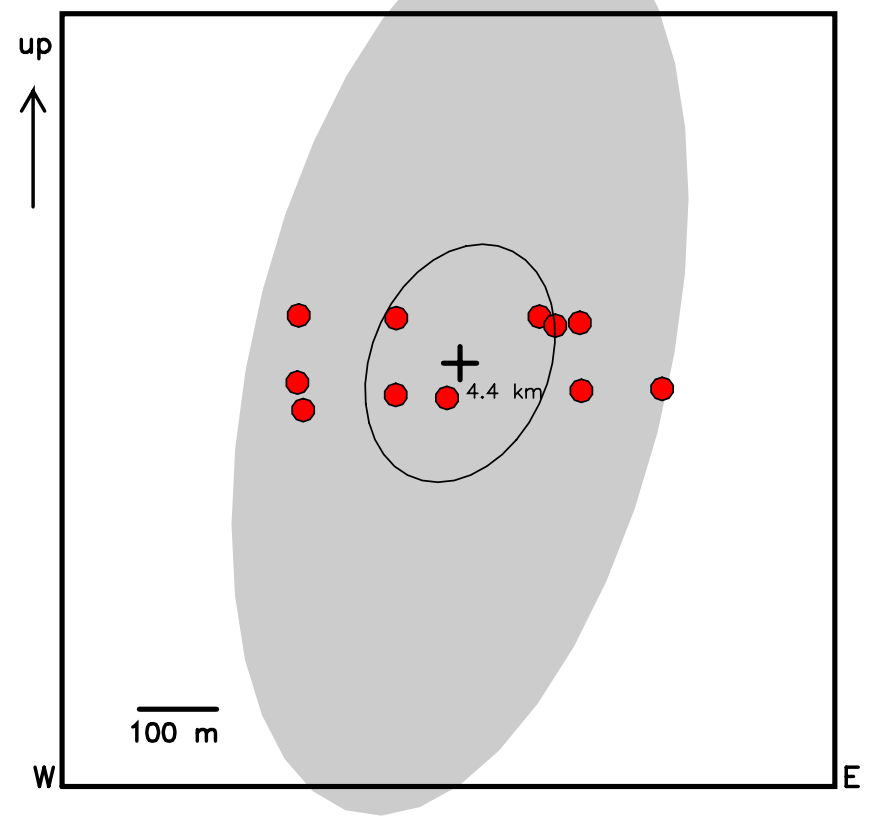

Figure 8. (a) Map and (b) cross-section showing precise relative locations (filled circles) for 11 very well-recorded earthquakes detected at the SMU network (Table 1, SMU events). The ellipsoids indicate estimates of the location uncertainty, with smaller ellipsoids showing the uncertainty in relative locations between events, and the larger (shaded) ellipsoids showing the absolute location uncertainty (see text). Plus (+) symbol near the center of the plot is the preferred centroid (mean) location of DFW focus at $32.855^{\circ} \mathrm{N}, 97.051^{\circ} \mathrm{W}, 4.4 \mathrm{~km}$ depth determined using the linear velocity model (see text). The 11 hypocenters and SWD location are plotted relative to this centroid location. Pluses labeled Wadati and 3 layer indicate how centroid location of DFW focus shifts when locations are determined using Wadati's method or with a conventional 3-layer velocity model (see text). Labeled arrows indicate directions of stations used to determine the precise relative locations; star labeled SWD is location of the saltwater disposal well. Solid borders enclose a 1-km square area. The color version of this figure is available only in the electronic edition. 


\section{Where Quakes Occurred: Earthquakes Reported by the NEIC}

None of the 11 earthquakes we relocated (Fig. 8 and Table 1, SMU events) were among the 14 events reported by the NEIC (Fig. 2 and Table 1, NEIC events); thus, the question remains: Do the 11 earthquakes located in this study and the NEIC events originate from the same focus? To address this question, we analyzed $P$ and $S$ arrivals at WMOK, which recorded both the 14 NEIC-reported earthquakes as well as the three largest earthquakes in Figure 8. At station WMOK $(S-P)$ picks for 16 of these 17 earthquakes ranged between $30.64 \mathrm{~s}$ and $30.88 \mathrm{~s}$; the $P$ for the remaining earthquake occurred within the coda of another event and could not be read accurately. The observed range in $(S-P)$ intervals $(\sim 0.2 \mathrm{~s})$ is approximately equivalent to the picking uncertainty for the $P$ arrival; thus, the data at WMOK are consistent with all events originating from the same or nearly the same focus.

We also analyzed $P$ and $S$ signals recorded at station DAL (Fig. 2) on the SMU campus about $25 \mathrm{~km}$ from the DFW focus. Seismograms at DAL were not useful for routine locations as neither $P$ and $S$ arrivals for DFW earthquakes are impulsive; for both phases the strongest signal arrives in the coda about $2-3 \mathrm{~s}$ after an initial emergent arrival. The site is noisy and DFW signals are identifiable only after applying a band-pass filter. Two three-component broadband seismographs at DAL recorded DFW events: the first instrument sampled data at $50 \mathrm{~Hz}$ and recorded 12 of the 14 NEIClocated earthquakes; the second instrument sampled data at $40 \mathrm{~Hz}$ and recorded four of the NEIC-recorded earthquakes and the three largest events relocated in this study.

To evaluate the range of $(S-P)$ intervals at DAL, we aligned filtered signals along an identifiable high-amplitude peak arriving at time $S_{c}$ in the $S$ coda and then compared relative arrival-time differences for a high-amplitude peak arriving at time $P_{c}$ in the $P$ coda. For the seven events recorded by the $40-\mathrm{Hz}$ instrument (Fig. 9), the range in $\left(S_{c}-P_{c}\right)$ intervals was $0.13 \mathrm{~s}$. The minimum $\left(S_{c}-P_{c}\right)$ interval was for the event SMU-11, an event already identified as having a signal unlike other DFW earthquakes (see Fig. 6). The range of $\left(S_{c}-P_{c}\right)$ intervals with this earthquake excluded was $0.08 \mathrm{~s}$. For the 12 NEIC-reported earthquakes recorded by the $50-\mathrm{Hz}$ instrument, the range in $\left(S_{c}-P_{c}\right)$ intervals was $0.07 \mathrm{~s}$.

An $(S-P)$ range of $0.08 \mathrm{~s}$ corresponds to a station-toepicenter variation of about $525 \mathrm{~m}$. For the 11 earthquakes located using the temporary local array (Fig. 8), the range in DAL-to-epicenter distances was $390 \mathrm{~m}$. Thus, the data recorded at DAL are consistent with the assertion that the 11 earthquakes we located and the 14 NEIC-located earthquakes are from the same or nearly the same focus.

As a final comparison of the 14 NEIC-reported and the 11 SMU-recorded epicenters, we cross correlated filtered signals recorded at WMOK to evaluate which pairs/groups of events were most and least similar (Fig. 10). We hypothesize that more highly correlated signals originate from clusters of sources having nearly the same focus. The cross correlation produced greater separations for $S$-phases recorded on the WMOK east component than for $P$ or $S$ phases recorded on the vertical or north components. For the SMU-recorded epicenters, this analysis found that many geographically close events were highly correlated (e.g., in the southern group in Fig. 8: SMU-7, SMU-8, and SMU-9; in the central group: SMU-1 and SMU-2; and in the northern group: SMU-4, SMU-6, and SMU-10). There were exceptions: for example, event SMU-11 was most unlike all remaining events; recall that SMU-11 was also identified as anomalous in Figure 6. SMU-3 was correlated slightly higher with the central group than with the northern group where it was located; SMU-5 was correlated more closely with the southern group than with the central group where it was located.

The cross-correlation analysis indicates that the NEICreported events were most similar to SMU-recorded events in either the southern cluster (NEIC-2, NEIC-6, NEIC-7, NEIC-8, and NEIC-11) or the north and central clusters (NEIC-3, NEIC-4, NEIC-5, NEIC-13, and NEIC-14). Thus, although the cross-correlation analysis does not confirm that all or nearly all of the 14 NEIC-reported events originated from hypocenters close to those of the 11 SMU-recorded earthquakes, it is consistent with that assertion.

\section{Proximity and Timing with Respect to Natural Gas Production Activities}

The natural gas production rate from the Barnett shale makes it the largest gas field in the United States, constituting some 5\% of U.S domestic production. The Barnett is of Mississippian ( 350 Ma) age and is present in a number of foreland basins (Delaware, Val Verde, Kerr, Fort Worth, Arkoma, and Black Warrior) north of the Ouachita thrust system. The Barnett is present throughout the subsurface of the Fort Worth basin $(55,000 \mathrm{sq} \mathrm{km})$ and terminates south and east at its footwall cutoff along the Ouachita thrust front. In the area of interest here the termination occurs in Dallas County, approximately $24 \mathrm{~km}$ east of the Tarrant County line (Flawn et al., 1961). In eastern Tarrant County, Pollastro et al. (2007) report that Barnett strata are at depths of about $2.2 \mathrm{~km}$ and average 150 meters thick, while the underlying Ellenburger Group dolomites are approximately 760 meters thick. Data from the Trigg well (Fig. 7) show the Barnett at slightly greater depth and the Ellenburger as somewhat thicker.

More than 12,000 wells have been completed in the Barnett shale of the Fort Worth basin in the past decade (Fig. 11). All the wells received hydraulic fracture treatments. Since 2002, most of the Barnett shale production wells have been horizontally drilled; typically, the horizontal section of each well has been hydraulically fractured at several positions along its length.

Although the Barnett shale has produced significant amounts of natural gas since 2001, principally in Wise, Denton, Johnson, and Tarrant counties, prior to 2002 there were few wells in highly urban Tarrant County. This changed 

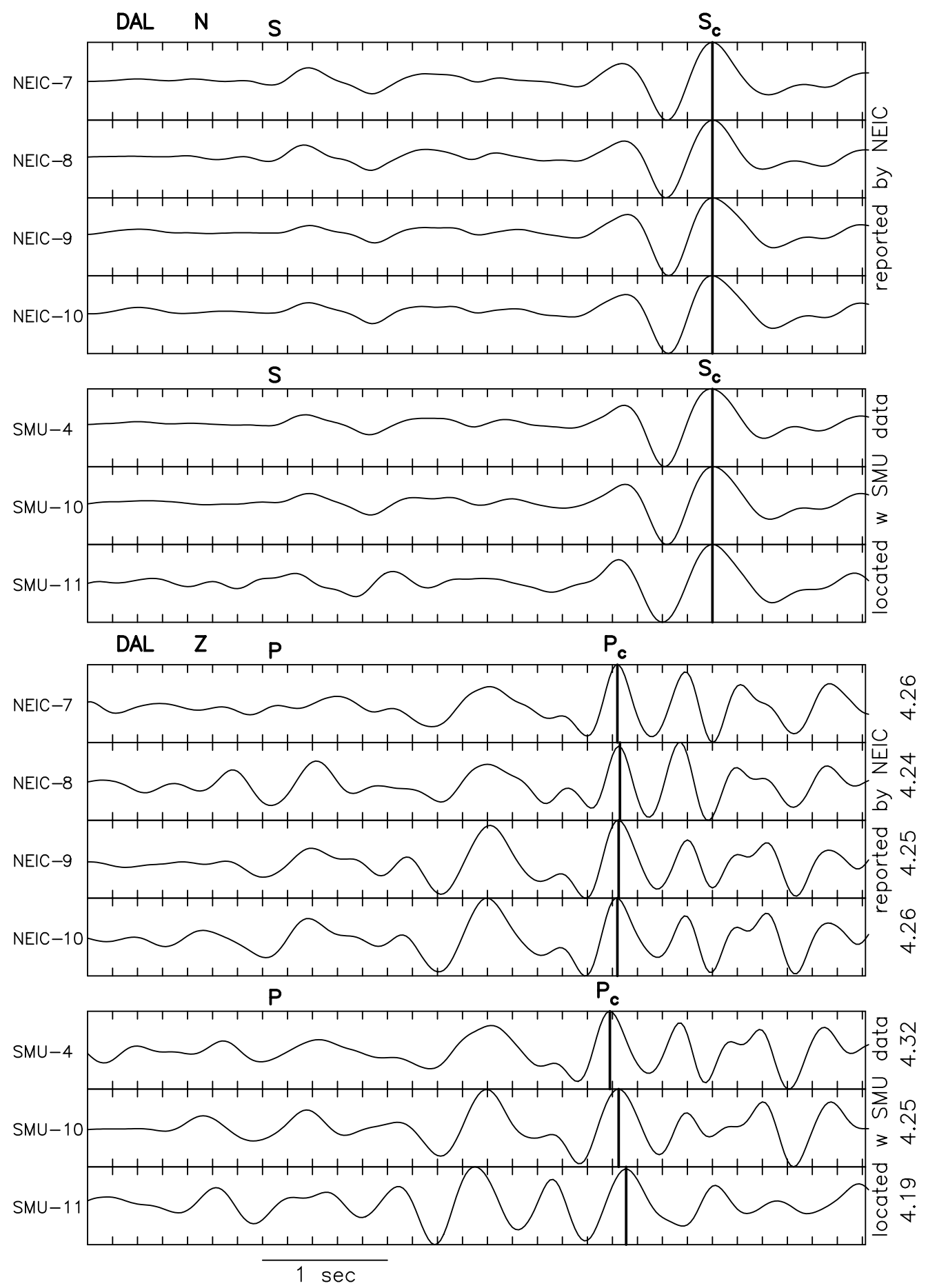

Figure 9. Comparison of arrival-time differences for NEIC-reported and SMU-located earthquakes. Plotted signals are $S$ arrivals and coda (top seven traces) and $P$ arrivals and coda (bottom seven traces) recorded at station DAL from four quakes reported by the NEIC and three quakes located using data from the SMU temporary network (see Table 1 and Fig. 8). The $S$ and $P$ labels indicate the approximate times of emergent $S$ and $P$ arrivals on the north (N)-component (top seven traces) and vertical (Z)-component (bottom seven traces); the vertical lines about 2.5-3.0 s later are higher-amplitude coda arrivals whose arrival times $S_{c}$ and $P_{c}$ can be picked precisely. For each event both N- and Z-component signals are aligned with the high-amplitude $S_{c}$ arrival (top seven traces); labels at left indicate origin times of the earthquakes; labels at right are the $\left(S_{c}-P_{c}\right)$ time differences. Note that the differences vary by $0.13 \mathrm{~s}$ and less, suggesting that the $\left(S_{c}-P_{c}\right)$ intervals at DAL are nearly the same for quakes located by NEIC and those located in this study.

partly because of favorable gas prices, but also because technological improvements involving multistaged hydraulic fracture procedures in horizontal wells made urban produc- tion feasible. Urban drilling was also facilitated by special regulations established by the city of Fort Worth, which supplement statewide regulations established by the Texas 


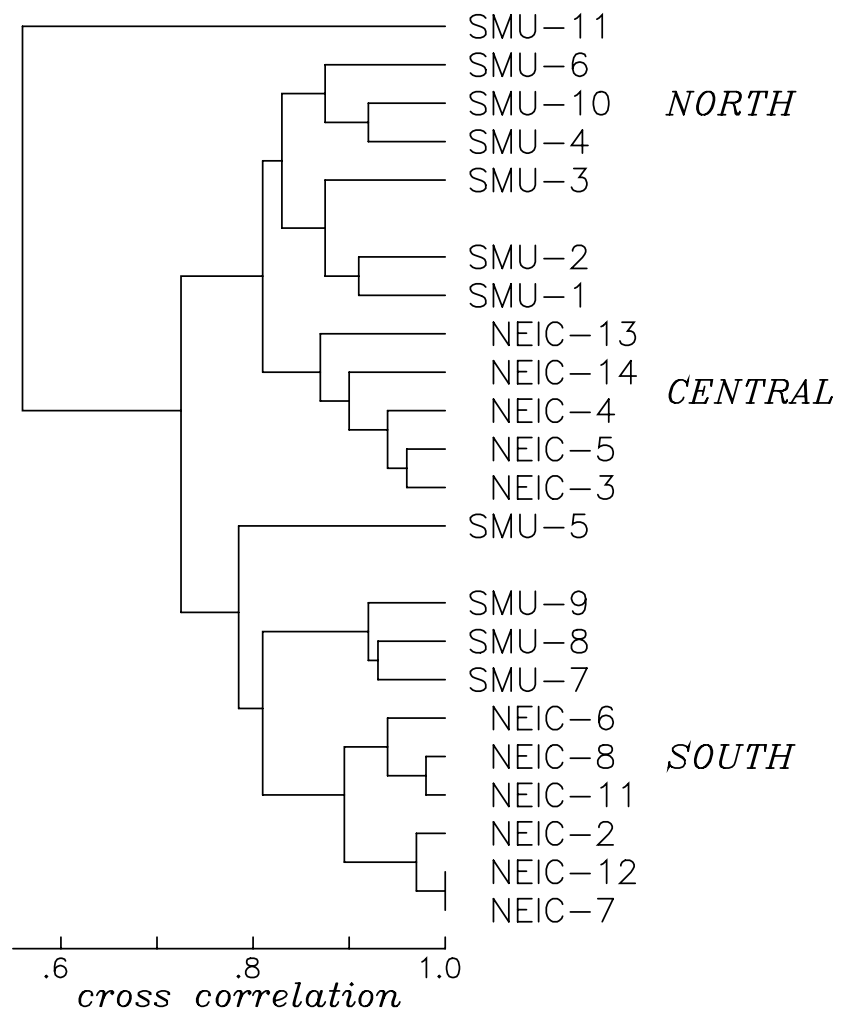

Figure 10. Dendrogram summarizing the cross-correlation analysis for $S$-phase signals recorded on the east component of WMOK for 11 of the earthquakes reported by the NEIC and the 11 SMU-recorded earthquakes; event identifiers such as SMU-11 or NEIC-6 are as in Table 1 and Figure 8. Horizontal axis is crosscorrelation between linked signal pairs; linked signals are merged sequentially before comparison with remaining signals. The dendrogram indicates that earthquakes within the south and the north-central clusters in Figure 8 produce highly similar signals; these signals are in turn highly similar to various of the NEICreported events.

Railroad Commission. Between January 2001 and February 2009, 2200 gas wells were completed in Tarrant and Dallas counties. Within $10 \mathrm{~km}$ of the DFW focus, there were no permitted gas wells prior to March 2007. Subsequently several producing wells were drilled on the DFW airport property to the north, west, and to the south; since January 2008, 13 wells were drilled and hydraulically fractured within $3 \mathrm{~km}$ of the DFW focus (Fig. 12). These nearest wells began production on dates ranging from June 2008 to March 2009.

The production of natural gas from shale involves four activities that conceivably could affect stress locally and/or induce seismic activity. These are (1) drilling wells; (2) hydraulic fracturing, which involves injecting fluids at high pressure into isolated sections of the well; (3) the removal of gas and other fluids during production; and (4) the disposal of these fluids, known as brines, usually by transporting them away from the production well and injecting them at "saltwater disposal" (SWD) wells into a formation where they will be contained permanently.
To dispose of brines recovered in the early phases of production at the DFW airport, two SWD wells were used, one south and one north of the DFW airport terminal (Fig. 12). The southern SWD well location $\left(32.852997^{\circ} \mathrm{N}\right.$, $97.050932^{\circ} \mathrm{W}$ ) is about $200 \mathrm{~m}$ south of the mean DFW focus as determined using the linear velocity model (Figs. 8 and 12). The permitted injection interval is from 10,752 to $13,729 \mathrm{ft}$ ( 3.3 to $4.2 \mathrm{~km}$ ), into the Ellenburger formation. Injection of brines commenced at this well on 12 September 2008, with injection volumes averaging $\sim 8,000-10,000$ barrels/day (1 barrel = 159 liters) through June 2009 (Fig. 13), and monthly tubing pressures ranging from 920 to 1968 psi (6.3-13.6 MPa). Inspection of reports filed with the Texas Railroad Commission for other SWD wells in Tarrant and Johnson counties found that injection rates typically ranged from 100,000-500, 000 barrels/month; thus, the 10,000 barrels/day rate is not unusual. For example, at the northern SWD well injection rates between January and March 2008 averaged 270,000 barrels/month, or about 9000 barrels/day.

\section{Discussion}

The principal conclusion of this study is that the DFW earthquakes arise from a highly localized source region at the Dallas-Fort Worth airport near $32.855^{\circ} \mathrm{N}, 97.051^{\circ} \mathrm{W}$, and having dimensions of about a kilometer (Fig. 12). Between 20 November and 2 December 2008, all earthquakes locatable by a local network had epicenters within about $600 \mathrm{~m}$ of the previously stated focus; precise relative locations of the best-recorded earthquakes indicated they formed a roughly linear group, trending about $25^{\circ} \mathrm{E}$ of north. Absolute locations determined using a velocity model constrained by measurements from a nearby well obtained depths of 4.4-4.8 km. It is plausible that all or nearly all DFW earthquakes arose from this source region; that is, between 30 October 2008 and 31 May 2009, at regional stations WMOK and DAL all the well-recorded events apparently from the DFW focus had nearly identical $(S-P)$ intervals.

A second important conclusion is that the disposal of brines accompanying natural gas production may have triggered or induced the DFW earthquakes; we find no evidence they were induced by drilling, hydraulic fracturing, or by the removal (production) of natural gas. Several types of evidence support these assertions. First, fluid injection for the purpose of enhanced petroleum production or waste disposal has caused earthquakes elsewhere (e.g., Hsieh and Bredehoeft, 1981; Nicholson and Wesson, 1990; Ake et al., 2005), including several locations in Texas (Davis and Pennington, 1989; Frohlich and Davis, 2002). Second, we are unaware of any previous reports of local felt earthquakes in Dallas and Tarrant counties, which have been settled since about 1850. Third, in September 2008 less than seven weeks before the DFW quakes began, injection commenced at a SWD well with a surface location only a few hundred meters from DFW epicenters. This SWD well extends to a depth of 


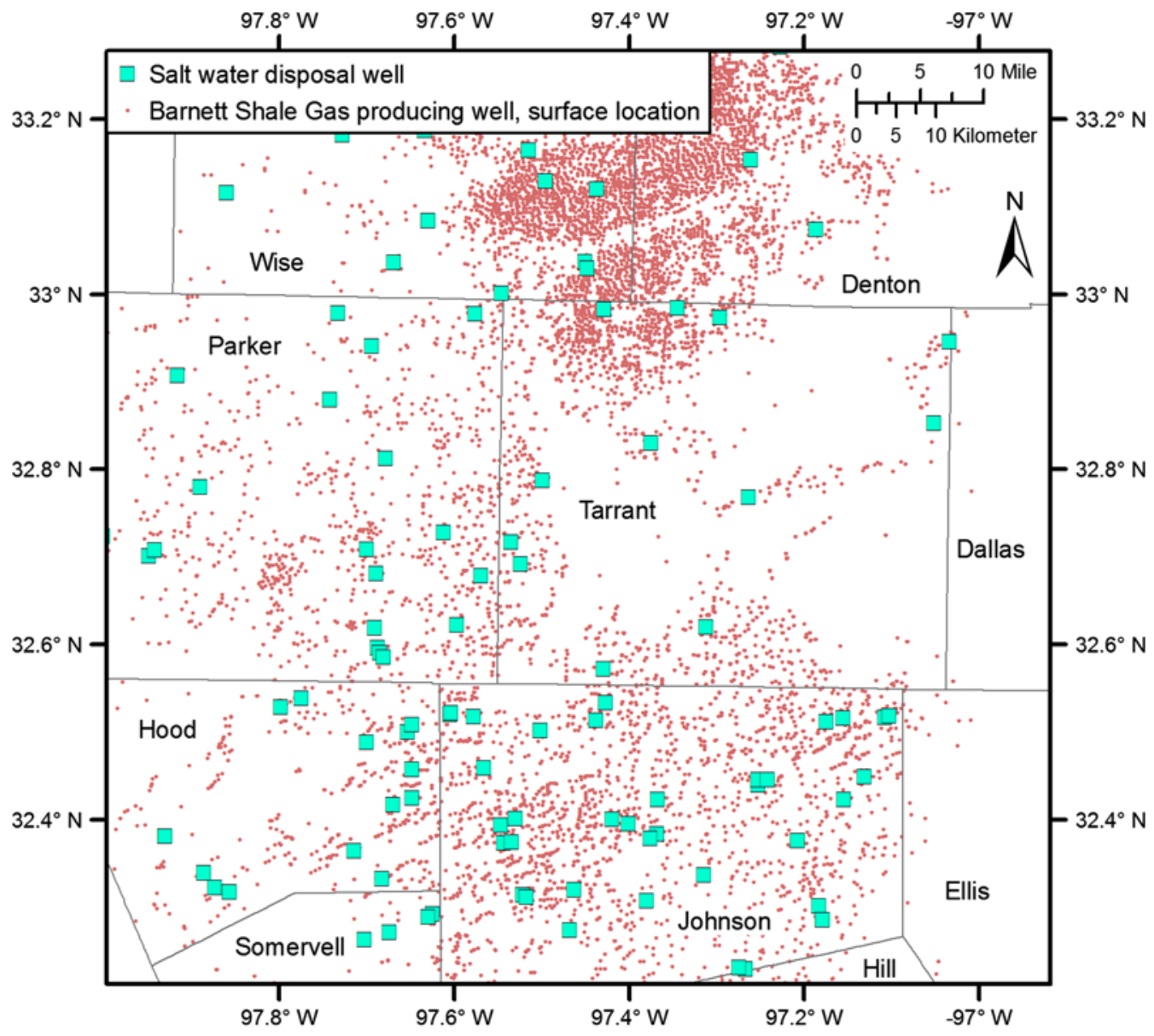

Figure 11. Map of producing natural gas wells and SWD wells in Tarrant and surrounding counties. Data are from the Texas Railroad Commission. The color version of this figure is available only in the electronic edition.

$4.2 \mathrm{~km}$, while our preferred hypocentral depth was $4.4 \mathrm{~km}$. Fourth, the locations and origin times of the earthquakes do not correlate with natural gas production well locations and times when drilling, hydrofracturing, and production were ongoing.

Some time ago Davis and Frohlich (1993) proposed a set of seven yes or no questions to help assess whether fluid injection may have caused observed earthquake activity (Table 4). For the DFW sequence, answers are yes for five questions; we do not have enough information to answer the remaining two.

One plausible explanation for the DFW sequence is that the brines injected into the Ellenburger migrated to a previously inactive fault, reactivating it and releasing residual tectonic stress. Various studies (e.g., Brudy et al., 1997) find that residual tectonic stresses within continental interiors are controlled by the strengths of optimally oriented preexisting faults, which are typically near failure. Ewing's (1990) tectonic map shows a northeast-trending normal fault in the subsurface (Fig. 2) that intersects the Dallas-Tarrant county line approximately at the location of the DFW focus. The map indicates the vertical offset on this fault is about $80 \mathrm{~m}$. According to Sullivan et al. (2006) and Tingay et al.
(2006), the present-day maximum principal stress direction in the Fort Worth basin is vertical, and the maximum horizontal stress is $\mathrm{N} 40^{\circ}-47^{\circ} \mathrm{E}$. Thus, stress is favorably oriented to reactivate normal-faulting motion along this mapped fault, and the trend of the epicenters in Figure 8 is consistent with seismic motion along such a reactivation.

Several other features of the DFW sequence are consistent with the hypothesis that the earthquakes, although induced, are controlled by tectonic stresses along a preexisting fault, rather than by frac fluids generating new fractures in intact rock. First, we observe a $b$ value of 1.30 (Fig. 5), a not unusual value for tectonic earthquakes (Frohlich and Davis, 1993). In contrast, studies of hydrofracture-induced microearthquakes, especially in tight-gas environments, typically find $b$ values of 2.0 and higher; indeed, Shapiro and Dinske (2009a, 2009b) report $b$ of 2.50 for microearthquakes produced by hydrofracturing the Barnett shale. Second, the cumulative number and cumulative moment of microearthquakes induced by hydrofracture tends to increase linearly with the volume of fluid injected (e.g., Phillips et al., 2002; Rutledge et al., 2004; Shapiro and Dinske, 2009b), rather than occurring in bursts or clusters as is observed for DFW in Figures 4 and 13. 


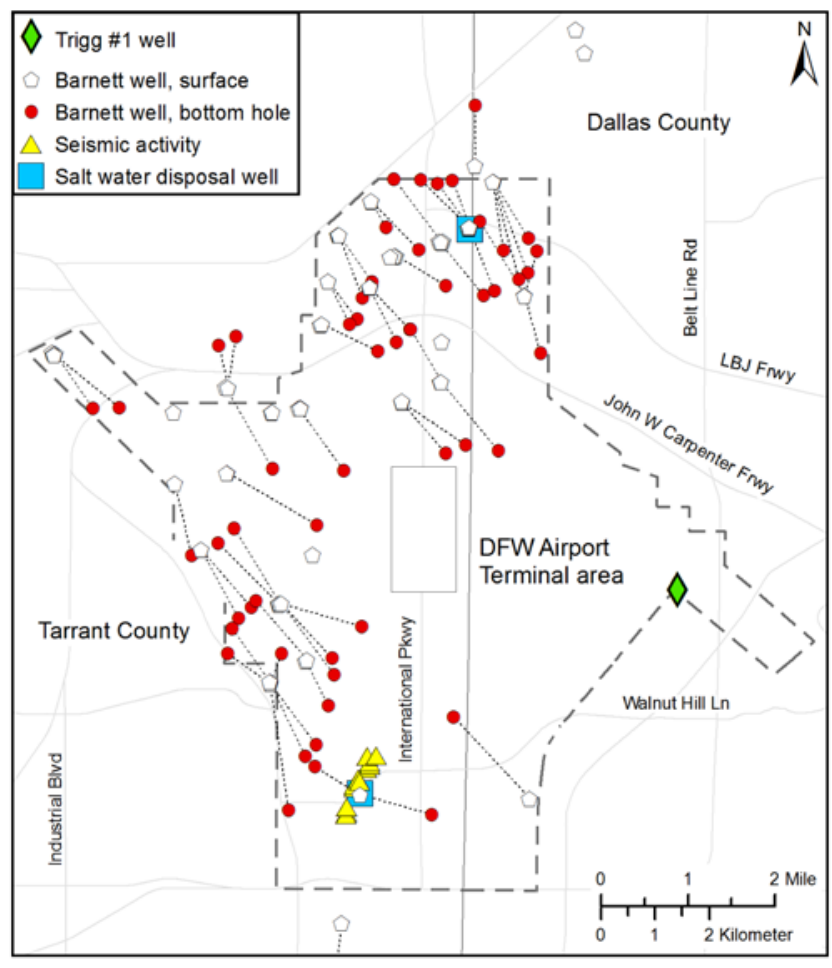

Figure 12. Map of region surrounding DFW airport, showing locations of earthquakes (triangles), producing gas wells (circles and pentagons), SWD wells (squares), and Trigg well no. 1 (diamond). Dashed line outlines DFW airport property; principal highways are labeled. The color version of this figure is available only in the electronic edition.

Finally, the largest DFW earthquakes have similar magnitudes ( $M$ 3.3) to historical natural earthquakes in northeast Texas. For example, on 9 June 1981 an $M 3.0$ earthquake occurred in the town of Center, $149 \mathrm{~km}$ southeast of Dallas-Fort Worth; on 18 September 1985 there was an $M 3.2$ in Valley View, $75 \mathrm{~km}$ to the north; and on 31 May 1997 an M 3.4 occurred in Commerce, $110 \mathrm{~km}$ to the northeast (see Frohlich and Davis, 2002). In contrast, most microearthquakes induced by hydrofracture have magnitudes of 2 or less (e.g., Cornet et al., 1997; Shapiro and Dinske, 2009b).

No local earthquakes, induced or tectonic, had been reported as felt in DFW prior to the 2008 activity; however, elsewhere in Texas there are several instances where earthquakes apparently are triggered by oil or gas production, by injection, or by waterflooding operations (Frohlich and Davis, 2002). The M 4.0 Mexia earthquake of 9 April 1932 occurred directly beneath the very productive Wortham field (Sellards, 1933; Yerkes and Castle, 1976). A sequence of earthquakes with magnitudes as great as 4.6 occurred near Snyder, Texas, and began only in 1974, after a massive waterflooding project began in the Cogdell field (Davis and Pennington, 1989). Earthquakes known to occur in Atascosa County near Fashing and Pleasanton are probably induced by natural gas production (e.g., see Pennington et al., 1986). The largest of the Fashing/Pleasanton earthquakes

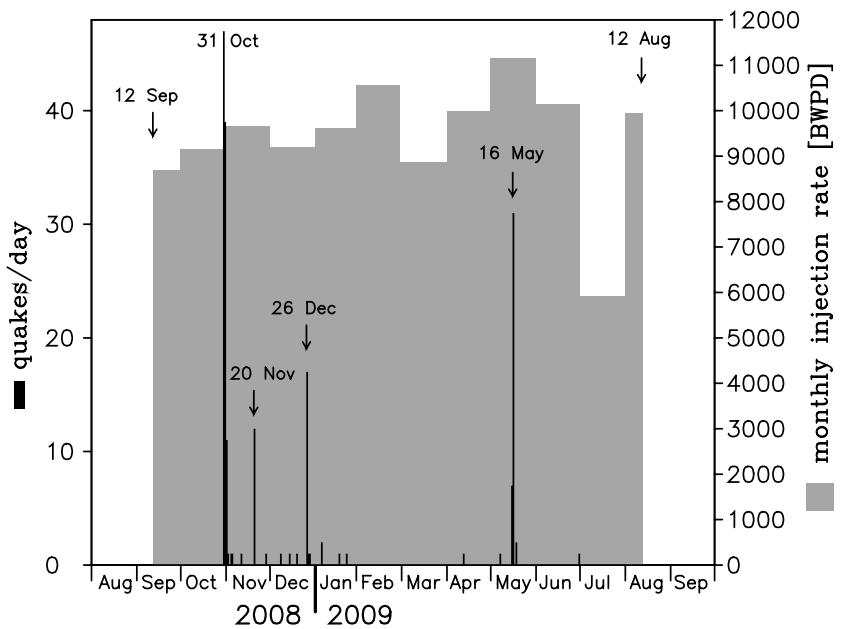

Figure 13. The DFW earthquakes and mean daily injection rates at the southwest SWD well (see Figs. 8 and 12). Earthquakes are as identified at WMOK (see text and Fig. 4); injection rates are daily means for the months indicated.

had a magnitude of 4.3 and occurred on 9 April 1993 (Davis et al., 1995). Finally, on 2 June 2009 a sequence of small, felt earthquakes ( $M 2.8$ and smaller) began near Cleburne, Texas, $65 \mathrm{~km}$ to the southwest of the DFW focus, but still in the Fort Worth basin and also an area of active gas production. A preliminary analysis of these earthquakes indicates that their epicenters lie within 1-2 km of injection wells and form a roughly linear cluster with dimension $\sim 2 \mathrm{~km}$ (Howe et al., 2010).

Like the DFW earthquakes, none of these allegedly induced earthquakes is significantly larger than regionally occurring natural earthquakes. In 1925, 1936, 1948, and 1952, the Texas panhandle experienced apparently natural earthquakes with magnitudes exceeding 5.0, larger than the 1978 Snyder earthquake. And in central Texas, there were earthquakes in 1887, 1891, and 1902 with magnitudes of

\section{Table 4}

Seven Questions Davis and Frohlich (1993) Posed to Help Assess whether Fluid Injection Induced an Earthquake or Earthquake Sequence

\begin{tabular}{ll}
\hline \multicolumn{1}{c}{ Question } & DFW Answer \\
\hline $\begin{array}{l}\text { Are these events the first known earthquakes } \\
\text { of this character in the region? }\end{array}$ & Yes \\
$\begin{array}{l}\text { Is there a clear correlation between injection } \\
\text { and seismicity? }\end{array}$ & Yes \\
$\begin{array}{l}\text { Are epicenters near wells (within } 5 \mathrm{~km} \text { ) } \\
\begin{array}{l}\text { Do some earthquakes occur at or near injection } \\
\text { depths? }\end{array}\end{array}$ & Yes \\
$\begin{array}{l}\text { If not, are there known geologic structures that } \\
\text { may channel flow to sites of earthquakes? }\end{array}$ & Yes \\
$\begin{array}{l}\text { Are changes in fluid pressures at well bottoms } \\
\text { sufficient to encourage seismicity? }\end{array}$ & Do not know \\
$\begin{array}{l}\text { Are changes in fluid pressures at hypocentral } \\
\text { distances sufficient to encourage seismicity? }\end{array}$ & Do not know \\
\end{tabular}


about 4.0, comparable in size to the 1932 Mexia earthquake. We are unaware of any instance where an earthquake firmly established as induced was significantly larger than regionally occurring natural earthquakes: for example, although the largest Denver earthquake occurred in 1967 and had a magnitude of 5.3, Denver had experienced an $M 6.2$ earthquake in 1882 (Hsieh and Bredehoeft, 1981). The magnitude of the largest Basel, Switzerland, injection-induced earthquake was 3.4 in 2006, but in 1356 there was a severe earthquake in Basel with magnitude of at least 6.5 (Majer et al., 2007).

Fortunately, there is no historical record of large (greater than $M$ 4.6) induced earthquakes in Texas. Thousands of injection wells exist in Texas, the vast majority of which produce no felt or instrumentally recorded seismicity (Frohlich and Davis, 2002). When induced earthquakes have occurred, they are small and produce little or no serious damage; for example, the 1978 Snyder earthquake broke several windows and caused mirrors and pictures to fall off walls (Davis and Pennington, 1989). The fault ruptures for typical induced earthquakes generally are too small to cause much damage; to date the largest DFW earthquake, with $M 3.3$, probably originated as a slip of about $2 \mathrm{~cm}$ on a fault rupture with a diameter of about 225 meters (see Davis and Frohlich, 1993; or Frohlich and Davis, 2002). In Texas, where large $(M>7)$ tectonic earthquakes and well-developed, seismically active, very long faults are unknown, it is highly improbable that the fluid volumes and pressures that are typical for SWD wells would affect a large enough area to induce a large earthquake.

More than 12,000 wells have been completed in the Barnett shale of the Fort Worth basin in the past decade (e.g., Fig. 11), and all of these wells received hydraulic fracture treatments. More than 200 SWD wells are active in the area of Barnett production. If one accepts that the DFW earthquakes were caused by brine injection at a SWD well, an important question is why earthquakes do not occur near other SWD wells.

As we have noted, our preferred explanation is that the injection at the south DFW airport SWD reactivated a favorably oriented mapped normal fault and released in situ tectonic stresses.

\section{Data and Resources}

All analyzed seismograms from station WMOK and from the SMU temporary network are archived at the IRIS Data Management Center and freely available to all. Information about well locations, depth, permitting history, and monthly injection volumes for Texas oil, gas, and disposal wells is regulated and archived by the Texas Railroad Commission and freely available to all.

\section{Acknowledgments}

Instrumentation for the SMU network was provided by the IRIS instrument pool under the PASSCAL Rapid Array Mobilization Program (RAMP). We thank scientists at Chesapeake Energy for valuable discussions and for providing the injection-rate information in Figure 13. Two anonymous reviewers made helpful suggestions that greatly improved this paper.

\section{References}

Ake, J., K. Mahrer, D. O'Connell, and L. Block (2005). Deep-injection and closely monitored induced seismicity at Paradox Valley, Colorado, Bull. Seismol. Soc. Amer. 95, 664-683, doi 10.1785/0120040072.

Brudy, M., M. D. Zoback, K. Fuchs, F. Rummel, and J. Baumgartner (1997). Estimation of the complete stress tensor to $8 \mathrm{~km}$ depth in the KTB scientific drill holes: Implications for crustal strength, J. Geophys. Res. 102, 18,453-18,475.

Cornet, F. H., J. Helm, H. Poitrenaud, and A. Etchecopar (1997). Seismic and aseismic slip induced by large scale fluid-injections, Pure Appl. Geophys. 150, 563-583.

Davis, S. D., and C. Frohlich (1993). Did (or will) fluid injection cause earthquakes?: Criteria for a rational assessment, Seismol. Res. Lett. 64, 207-224.

Davis, S. D., and W. D. Pennington (1989). Induced seismic deformation in the Cogdell oil field of West Texas, Bull. Seismol. Soc. Amer. 79, 1477-1495.

Davis, S. D., P. Nyffenegger, and C. Frohlich (1995). The 9 April 1993 earthquake in south-central Texas: Was it induced by fluid withdrawal?, Bull. Seismol. Soc. Amer. 85, 1888-1895.

Ewing, T. (1990). Tectonic map of Texas, published by Bureau of Economic Geology, University of Texas, Austin, Texas.

Flawn, P. T., A. Goldstein, P. B. King, and C. E. Weaver (1961). The Ouachita System, Bureau of Economic Geology 6120, University of Texas, Austin, Texas, 385.

Frohlich, C. (1993). Users Manual for TexFlex-0.5: The Texas Flexible, Practical Program for Locating Seismic Events, Univ. Texas Inst. Geophys. Tech. Rept. No. 128, Austin, Texas, 64 pp.

Frohlich, C. (2006). Deep Earthquakes, Cambridge Univ. Press, Cambridge, U.K., 574 pp.

Frohlich, C., and S. D. Davis (1993). Teleseismic $b$ values; Or, much ado about 1.0, J. Geophys. Res. 98, 641-644.

Frohlich, C., and S. D. Davis (2002). Texas Earthquakes, University of Texas Press, Austin, Texas, 275 pp.

Frohlich, C., E. Potter, C. Hayward, and B. Stump (2010). Dallas-Fort Worth earthquakes coincident with activity associated with natural gas production, Leading Edge 29, 270-275.

Geotechnical Corporation (1964). Deep-Hole Site Report, Trigg No. 1, Dallas County, Texas, Geotechnical Corporation Tech. Rept. 64-100.

Howe, A. M., C. T. Hayward, B. W. Stump, and C. Frohlich (2010). Analysis of recent earthquakes in Cleburne, Texas, Seismol. Res. Lett. 81, 379.

Hsieh, P. A., and J. S.w Bredehoeft (1981). A reservoir analysis of the Denver earthquakes-A case study of induced seismicity, J. Geophys. Res. 86, 903-920.

Majer, E. L., R. Baria, M. Stark, S. Oates, J. Bommer, B. Smith, and H. Asanuma (2007). Induced seismicity associated with Enhanced Geothermal Systems, Geothermics 36, 185-222, doi 10.1016/ j.geothermics.2007.03.003.

Montgomery, S. L., D. M. Jarvie, K. A. Bowker, and R. M. Pollastro (2005). Mississippian Barnett shale, Fort Worth basin, north-central Texas: Gas-shale play with multi-trillion cubic foot potential, AAPG Bull. 89, 155-175, doi 10.1306/09170404042.

Nicholson, C., and R. L. Wesson (1990). Earthquake hazard associated with deep well injection: A report to the U.S. Environmental Protection Agency, U.S. Geol. Surv. Bull. 1951, 74 pp.

Pennington, W. D., S. D. Davis, S. M. Carlson, J. Dupree, and T. E. Ewing (1986). The evolution of seismic barriers and asperities caused by the depressuring of fault planes in oil and gas fields of south Texas, Bull Seismol. Soc. Amer. 76, 939-948.

Phillips, W., J. Rutledge, L. House, and M. Fehler (2002). Induced microearthquake patterns in hydrocarbon and geothermal reservoirs: Six case studies, Pure Appl. Geophys. 159, 345-369. 
Pollastro, R. M., D. M. Jarvie, R. J. Hill, and C. W. Adams (2007). Geologic framework of the Mississippian Barnett shale, Barnett-Paleozoic total petroleum system, Bend arch-Fort Worth Basin, Texas, AAPG Bull. 91, 405-436, doi 10.1306/103000606008.

Rutledge, J. T., W. S. Phillips, and M. J. Mayerhofer (2004). Faulting induced by forced fluid injection and fluid flow forced by faulting: An interpretation of hydraulic-fracture microseismicity, Carthage Cotton Valley Gas Field, Texas, Bull. Seismol. Soc. Amer. 94, $1817-1830$.

Sellards, E. H. (1933). The Wortham-Mexia, Texas, earthquake. Contributions to Geology, Univ. Texas Bull. 3201, 105-112.

Shapiro, S. A., and C. Dinske (2009a). Fluid-induced seismicity: Pressure diffusion and hydraulic fracturing, Geophys. Prospect. 57, 301-310, doi $10.1111 / \mathrm{j} .1365-2478.2008 .00770 . x$.

Shapiro, S. A., and C. Dinske (2009b). Scaling of seismicity induced by nonlinear fluid-rock interaction, J. Geophys. Res. 114, B09307, doi 10.1029/2008JB006145.

Suckale, J. (2009). Induced seismicity in hydrocarbon fields, Adv. Geophys. 51, 55-106, doi 10.1016/S0065-2687(09)05107-3.

Suckale, J. (2010). Moderate-to-large seismicity induced by hydrocarbon production, Leading Edge 29, 310-319.

Sullivan, E. C., K. J. Marfurt, A. Lacazette, and M. Ammerman (2006) Application of new seismic attributes to collapse chimneys in the Fort Worth Basin, Geophys. 71, B111-B119, doi 10.1190/ 1.2216189.

Tingay, M. R. P., B. Muller, J. Reinecker, and O. Heidbach (2006). State and origin of the present-day stress field in sedimentary basins: New results from the World Stress Map Project, in Proc.of the 41st U.S. Symposium on Rock Mechanics: 50 years of rock mechanics: Landmarks and future challenges: Golden, Colorado, CD-ROM ARMA/USRMS 06-1049, 14 pp.

Wadati, K. (1928). Shallow and deep earthquakes, Geophys. Magazine 1, 161-202.

Yerkes, R. F., and R. O. Castle (1976). Seismicity and faulting attributable to fluid extraction, Eng. Geol. 10, 151-167.

Institute for Geophysics

Jackson School of Geosciences

University of Texas at Austin

10100 Burnet Rd. (R2200)

Austin, Texas 78758-4445

cliff@ig.utexas.edu

(C.F.)

Huffington Department of Earth Sciences

Southern Methodist University

Dallas, Texas 75275

(C.H., B.S.)

Bureau of Economic Geology Jackson School of Geosciences

University of Texas at Austin

Austin, Texas 78758

(E.P.)

Manuscript received 17 May 2010 